\title{
Transcatheter aortic valve implantation and hybrid coronary revascularization in a patient with severe aortic stenosis, complex coronary artery disease, and porcelain aorta
}

\author{
Jacek Legutko' ' Łukasz Wiewiórka², Jacek Piątek³ , Jarosław Trębacz² , Robert Sobczyński ${ }^{4}$, Maciej Stąpór², \\ Janusz Konstanty-Kalandyk³, Bogusław Kapelak³ ${ }^{3}$ Paweł Kleczyński ${ }^{1}$ \\ 'Institute of Cardiology, Department of Interventional Cardiology, John Paul II Hospital, Jagiellonian University Medical College, Kraków, Poland \\ ${ }^{2}$ Clinical Department of Interventional Cardiology, John Paul II Hospital, Kraków, Poland \\ ${ }^{3}$ Institute of Cardiology, Department of Cardiac Surgery and Transplantation, John Paul II Hospital, Jagiellonian University Medical College, Kraków, Poland \\ ${ }^{4}$ Clinical Department of Cardiac Surgery and Transplantation, John Paul II Hospital, Kraków, Poland
}

\author{
Correspondence to: \\ Prof. Jacek Legutko, MD, PhD, \\ FESC, \\ Department of Interventional \\ Cardiology, John Paul II Hospital \\ Jagiellonian University Medical \\ College, Institute of Cardiology, \\ Prądnicka 80, 31-202 Kraków \\ Poland, \\ phone: +48 1261435 01, \\ e-mail: jacek.legutko@uj.edu.pl \\ Copyright by the Author(s), 2021 \\ Kardiol Pol. 2021; \\ 79 (11): 1286-1287; \\ DOI: 10.33963/KP.a2021.0097 \\ Received: \\ June 27, 2021 \\ Revision accepted: \\ August 30, 2021 \\ Published online: \\ August 31, 2021
}

Transcatheter aortic valve implantation (TAVI) and percutaneous coronary intervention $(\mathrm{PCl})$ are recommended therapeutic options in patients with severe aortic stenosis (AS), concomitant coronary artery disease (CAD), and porcelain aorta [1, 2]. However, in patients with complex left main coronary artery (LM) and multivessel disease (MVD), $\mathrm{PCl}$ remains a high-risk procedure associated with worse long-term clinical outcomes compared to surgical revascularization [3]. Hybrid coronary revascularization $(\mathrm{HCR})$, a minimally invasive revascularization strategy, in which the durability of the internal mammary artery to the left anterior descending artery graft is combined with advantages of $\mathrm{PCl}$ to treat remaining lesions, may be beneficial for such patients [4].

A 63-year-old female was admitted to our center due to severe dyspnea with accompanying chest pain. Echocardiography revealed severe AS (aortic valve area [AVA] $0.5 \mathrm{~cm}^{2}$ and a mean pressure gradient $77 \mathrm{~mm} \mathrm{Hg}$ with mildly reduced left ventricular ejection fraction [LVEF] 48\%) (Figure 1A). Coronary angiography showed MVD, with chronic total occlusion of right coronary artery (RCA), critical LM stenosis, left anterior descending artery (LAD), and ostial circumflex (LCX) (Figure 1B). Calculated Syntax Score I was 33 points, 4-year mortality based on Syntax Score II was $11.3 \%$ for (PCI) and $3.9 \%$ for coronary artery bypass grafting (CABG). Fluoroscopy showed extensive calcifications in the ascending aorta, recognized by computed tomography as porcelain aorta (Figure 1A). The patient was presumed as a low risk for surgical valve replacement (logistic EuroScore II 2.2\% and STS score 2.1\%) and his case was discussed with the Heart Team. Multiple treatment options have been considered but due to the presence of porcelain aorta, classic surgery has not been recommended. Due to very recent circulatory decompensation, the patient was scheduled for balloon aortic valvuloplasty (BAV) as the first step of treatment. The problem remained with coronary revascularization. Percutaneous revascularization in MVD involving LM is associated with a very high risk of failure, especially in the case of chronic occlusion of the RCA. Similar concerns remained with TAVI. Due to the aforementioned circumstances, a hybrid approach was proposed, including minimally invasive coronary artery bypass (MIDCAB) LAD before $\mathrm{TAVl}$, and afterwards percutaneous revascularization of LM/LCx. Balloon aortic valvuloplasty, complicated with successfully managed ventricular fibrillation, was performed during index hospital stay with VACS II 20 mm (Osypka AG, Rheinfelden, Germany) with a mean pressure gradient drop to $30 \mathrm{~mm} \mathrm{Hg}$. Two months later a successful MIDCAB-LAD was performed (Figure 1C). In the next step, the TAVI procedure with a self-expandable Portico $25 \mathrm{~mm}$ valve (Abbott, Santa Clara, CA, USA) was performed with the use of commissural alignment technique and without pacing (Figure 1C). Finally, during the same hospital stay, we confirmed patency of the left internal mammary artery LAD graft, and a PCl of LM/Cx was performed via transradial approach with a $7 \mathrm{~F}$ Judkins left 

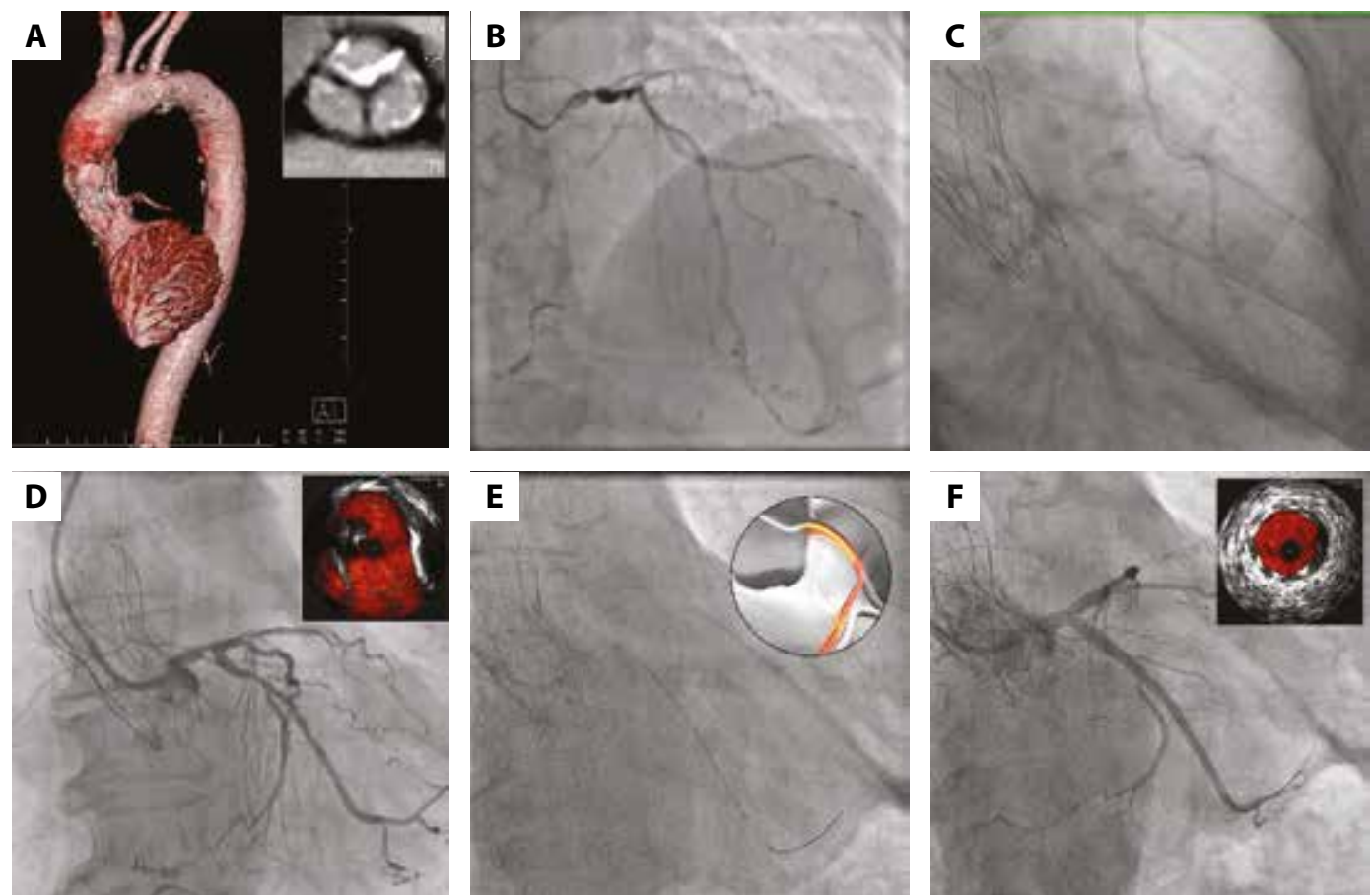

Figure 1. A. Computed tomography: severe calcification of the aortic valve and the ascending aorta (porcelain aorta); calcification in the distal left main coronary artery. B. Baseline angiography: anteroposterior cranial view. Critical left main stenosis with collateral circulation from the left coronary artery to the chronic occluded right coronary artery. C. Left anterior oblique view. The optimal result of LIMA-LAD grafting. TAVI prosthesis. D. Coronary angiography before the left main coronary artery and the left circumflex artery stenting. Antero-posterior caudal view. IVUS of the ostial left main with calcifications and valve struts. E. Coronary angioplasty, performed with the support of guide extension catheter - Guideliner. F. Final angiography - anteroposterior caudal view. The optimal result of stenting with appropriate stents position confirmed in IVUS

Abbreviations: IVUS, intravascular ultrasound imaging; LIMA-LAD, left internal mammary artery-left anterior descending artery; TAVI, transcatheter aortic valve implantation

3.5 guiding catheter (Launcher, Medtronic, Minneapolis, MN, USA) (Figure 1D-F). Due to the presence of self-expandable aortic bioprosthesis, $\mathrm{PCl}$ was much more challenging, but not impossible with the support of a guide extension device (Guideliner, Teleflex, Wayne, NJ, USA) (Figure 1E). Two drug eluting stents (DES) were implanted $(2.75 \times 48 \mathrm{~mm}$ and $3.5 \times 18 \mathrm{~mm}$ ) under intravascular ultrasound guidance (Figure 1F). No complications occurred during each hospital stay and in the 6-month follow-up.

Porcelain aorta presents potential problems for surgery in low-risk surgery patients. The combination of hybrid procedures:TAVI, off-pump CABG, or percutaneous revascularization are valuable and promising methods for the treatment of severe AS and CAD. Moreover, currently there is an ongoing discussion about the necessity and timing of myocardial revascularization before TAVI, even after a coronary physiology assessment confirming ischemia [5].

\section{Article information}

Conflict of interests: None declared.

Open access: This article is available in open access under Creative Common Attribution-Non-Commercial-No Derivatives 4.0 International (CC BY-NC-ND 4.0) license, allowing to download articles and share them with others as long as they credit the authors and the publisher, but without permission to change them in any way or use them commercially. For commercial use, please contact the journal office at kardiologiapolska@ptkardio.pl.

How to cite: Legutko J, Wiewiórka $Ł$, Piątek J, et al. Transcatheter aortic valve implantation and hybrid coronary revascularization in a patient with severe aortic stenosis, complex coronary artery disease, and porcelain aorta. Kardiol Pol. 2021; 79(11): 1286-1287, doi: 10.33963/KP.a2021.0097.

\section{REFERENCES}

1. Falk V, Baumgartner H, Bax JJ, et al. ESC Scientific Document Group. 2017 ESC/EACTS Guidelines for the management of valvular heart disease. Eur Heart J. 2017; 38(36): 2739-2791, doi: 10.1093/eurheartj/ehx391, indexed in Pubmed: 28886619.

2. Parma R, Zembala MO, Dąbrowski M, et al. Transcatheter aortic valve implantation. Expert Consensus of the Association of Cardiovascular Interventions of the Polish Cardiac Society and the Polish Society of Cardio-Thoracic Surgeons, approved by the Board of the Polish Cardiac Society and National Consultants in Cardiology and Cardiac Surgery. Kardiol Pol. 2017; 75(9): 937-964, doi: 10.5603/KP.2017.0175, indexed in Pubmed: 28895996.

3. Neumann FJ, Sousa-Uva M, Ahlsson A, et al. ESC Scientific Document Group. 2018 ESC/EACTS Guidelines on myocardial revascularization. Eur Heart J. 2019; 40(2): 87-165, doi: 10.1093/eurheartj/ehy394, indexed in Pubmed: 30165437.

4. McKiernan M, Halkos ME. Hybrid coronary revascularization: are we there yet? Curr Opin Cardiol. 2020; 35(6): 673-678, doi: 10.1097/HCO.0000000000000784, indexed in Pubmed: 32852342.

5. Kleczynski P, Dziewierz A, Rzeszutko L, et al. Hyperemic versus non-hyperemic indexes for coronary physiology assessment in patients with severe aortic stenosis. Adv Med Sci. 2021 [Epub ahead of print]; 66(2): 366-371, doi: 10.1016/j.advms.2021.07.008, indexed in Pubmed: 34315011. 